\title{
Efficacy of Self-Directed Exposure Using Smart Phone Technology: First versus Third Person Perspective
}

\author{
Matthew C. Arias
}

Follow this and additional works at: https://researchrepository.wvu.edu/etd

\section{Recommended Citation}

Arias, Matthew C., "Efficacy of Self-Directed Exposure Using Smart Phone Technology: First versus Third Person Perspective" (2017). Graduate Theses, Dissertations, and Problem Reports. 5120.

https://researchrepository.wvu.edu/etd/5120

This Thesis is protected by copyright and/or related rights. It has been brought to you by the The Research Repository @ WVU with permission from the rights-holder(s). You are free to use this Thesis in any way that is permitted by the copyright and related rights legislation that applies to your use. For other uses you must obtain permission from the rights-holder(s) directly, unless additional rights are indicated by a Creative Commons license in the record and/ or on the work itself. This Thesis has been accepted for inclusion in WVU Graduate Theses, Dissertations, and Problem Reports collection by an authorized administrator of The Research Repository @ WVU. For more information, please contact researchrepository@mail.wvu.edu. 


\title{
Efficacy of Self-Directed Exposure Using Smart Phone Technology: \\ First versus Third Person Perspective
}

\author{
Matthew C. Arias \\ Thesis submitted to the \\ Eberly College of Arts and Sciences \\ at West Virginia University \\ in partial fulfillment of the requirements for the degree of \\ Master of Science in Psychology
}

Daniel W. McNeil, Ph.D., Chair

Robert Stuchell, D.M.D.

Constance Toffle, Ph.D.

Department of Psychology

Morgantown, West Virginia

2016

Keywords: exposure, smartphone, technology, specific phobia, dental fear Copyright 2016 Matthew C. Arias 


\begin{abstract}
Efficacy of Self-Directed Exposure Using Smart Phone Technology:
\end{abstract}

First versus Third Person Perspective

\begin{abstract}
Matthew C. Arias
Exposure therapy, including its self-directed forms, is effective for treatment of specific phobias. Nevertheless, there are issues with patient adherence in the use of exposure therapy, including its self-directed formats. Technological advancements, as with smartphones, may improve adherence to self-directed exposure therapy, perhaps due to exposure stimuli being more readily accessible. Thus, there is a need to examine how presenting phobic material on a smartphone might promote increased adherence in conducting self-directed exposure. Additionally, exposure can incorporate phobic material from different perspectives (i.e., first-person or third-person), which is one factor that may impact treatment effectiveness. Participants $(N=36)$ were randomly assigned to a treatment or control condition, and completed a pre-assessment and then a post-assessment two weeks later. The assessment consisted of a multimodal approach (e.g., self-report, physiological response, and overt behavior). Participants in the treatment condition were instructed to watch a standard exposure video of a dental examination and prophylaxis three times daily for two weeks. One week of videos was shown in a first-person perspective and the same video was shown in a third-person perspective for one week. Results indicated that the smartphone-based stimuli were utilized by the participants, and that the treatment was acceptable to them. There was a significant interaction of time by condition for self-reported anxiety during a behavioral avoidance task. Participants in the treatment condition had significantly lower selfreported anxiety at the post-assessment compared to the pre-assessment, and no change in anxiety was found for the control group from pre- to post-assessment. A significant decrease in heart rate and trait anxiety was found from pre- to post-assessment for all participants. Results demonstrated the potential utility of smartphone-based self-directed exposure therapy for specific phobia.
\end{abstract}


Table of Contents

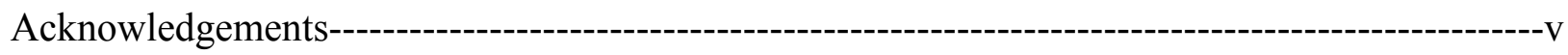

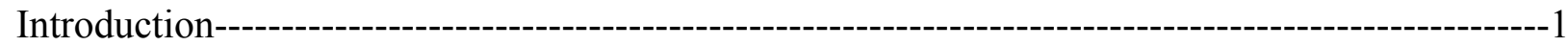

Phobic Disorders--------------------------------------------------------------------------------------1

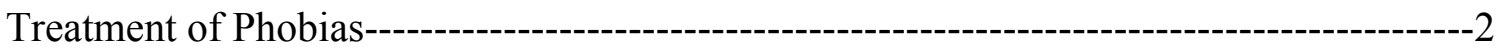

Mechanisms Involved in Exposure-----------------------------------------------------------------3

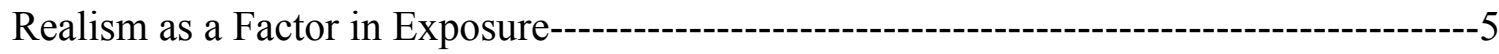

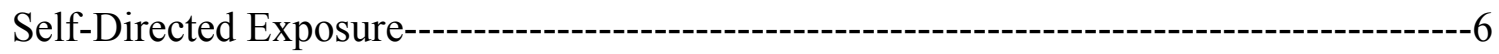

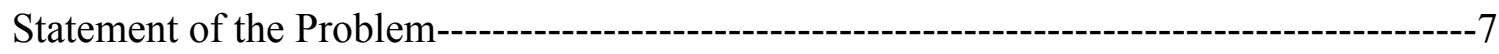

Research Questions and Hypotheses-----------------------------------------------------------------8

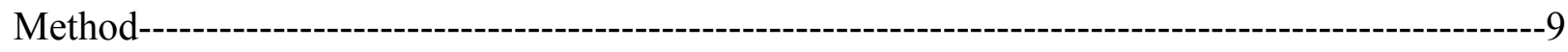

Experimental Design------------------------------------------------------------------------------------9

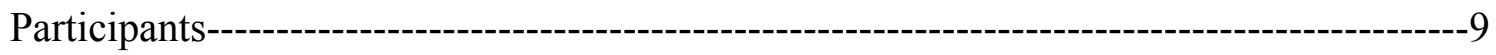

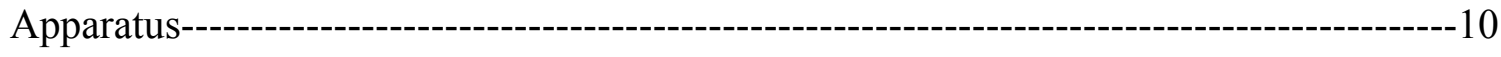

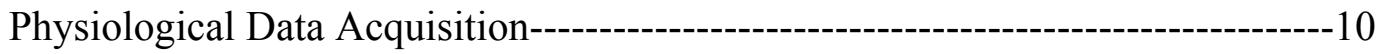

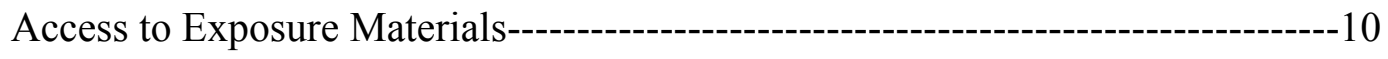

Self-Report Measures --------------------------------------------------------------------------------10

Demographic and General Dental Information Questionnaire------------------------11

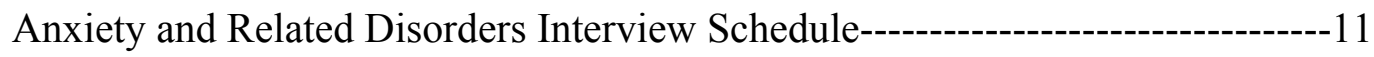

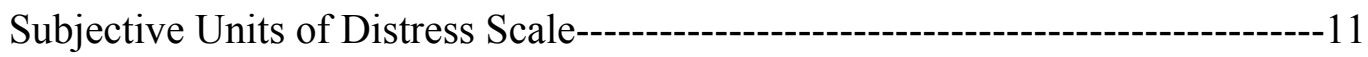

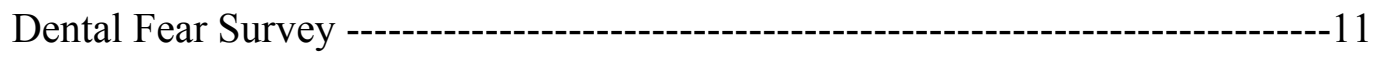

IGroup Presence Questionnaire------------------------------------------------------------12 


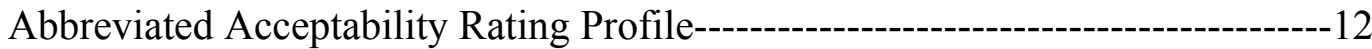

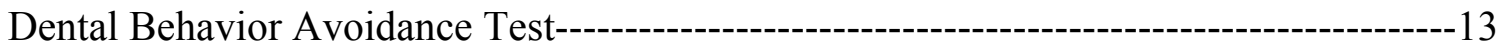

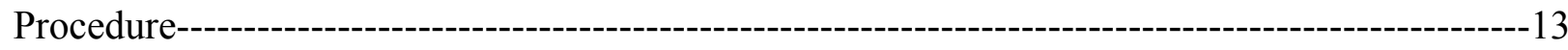

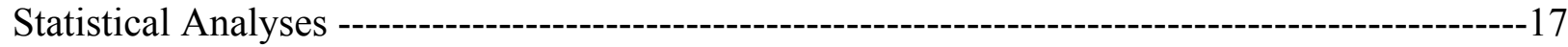

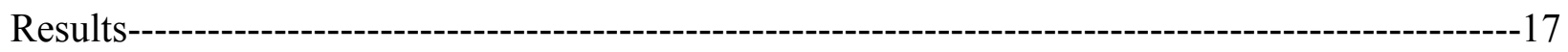

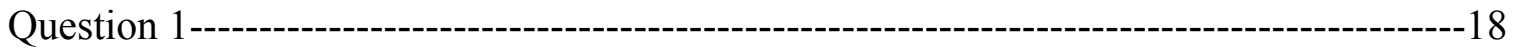

Question 2--

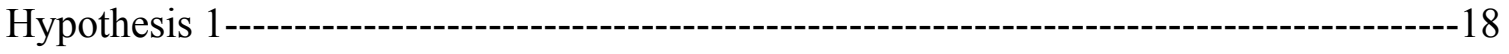

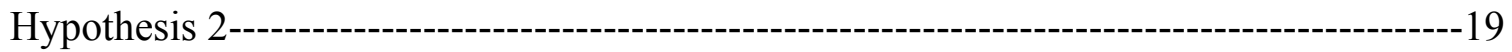

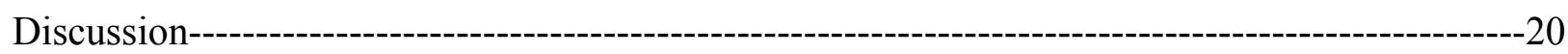

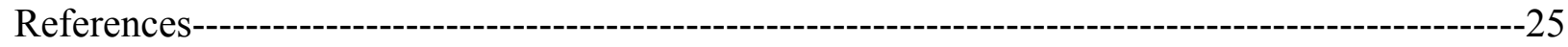

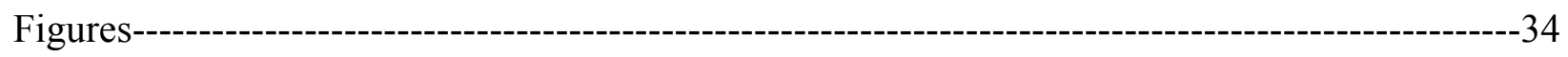

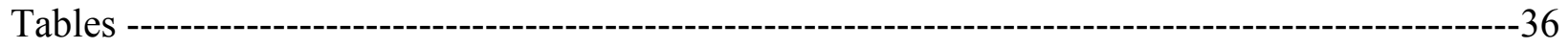

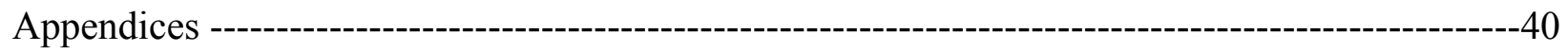

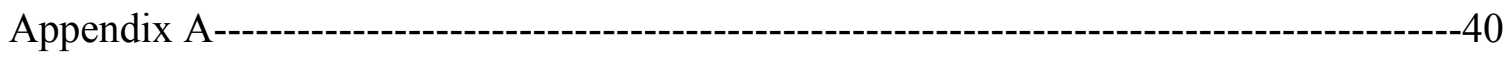

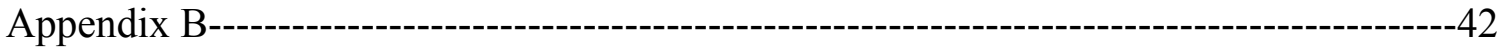

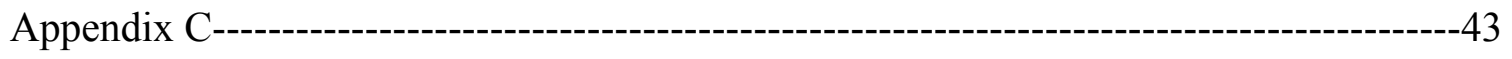

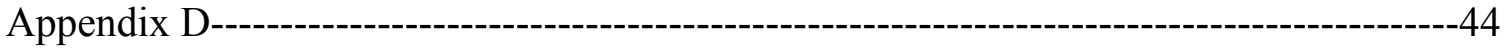

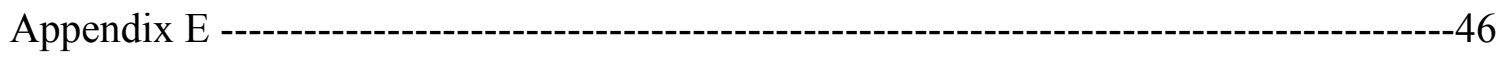

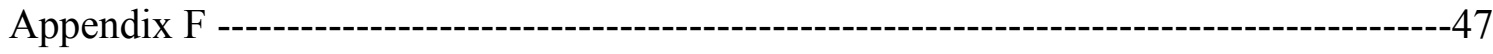




\section{Acknowledgements}

Conducting this study has been a meaningful and rewarding experience, and I am truly grateful for all of the individuals who made it possible. I am thankful for the time and guidance offered to me by the members of my thesis committee, Daniel McNeil, Connie Toffle, and Bob Stuchell. Dan has been wonderful with his direct guidance and feedback at all junctions of this project. In addition to serving as my committee chair, Dan has always spurred me to conduct meaningful research in a supporting and caring way. I truly believe that the project would not have been completed without his assistance. Connie has been influential with her support throughout this project. She has provided great feedback to improve this study, and has always been supportive of me. Bob warrants special thanks for agreeing to fill in as a committee member. Also, Bob was extremely important with the development of the exposure vides, and even starred as the dentist. Thanks, too, are extended to Judy Grubb, who was the dental hygienist in the videos.

Gratitude should be given to all members of the Anxiety, Psychophysiology, and Pain Research Laboratory, Sarah Hayes, Remy Black, Casey Wright, and Cierra Edwards. I am appreciative for the hard work they have demonstrated with helping during data collection, and being flexible with sharing the lab space. Also, the undergraduates in the lab have provided a tremendous amount of help with data collection and imputation. Special thanks to Rachael Petrie, Cal Wilson, and Deja Clement for spending many hours helping with my project.

I would be amiss if I did not recognize those outside of my lab who have been an essential part for completing this project. Tyler Wurtz, Jarred Gallegos, and Dan Stephenson have been incredible "dentists," and have been flexible with scheduling participants at all times in the day and week. I am grateful for their time and efforts in helping me succeed. 
Lastly, I want to thank my family for the support they have shown during this busy time in my life. In particular, I thank my wife, Nicole, who has been understanding with my late nights and busy weekends. Also, I want to thank all of my family because they have been so supportive of my endeavors. I am especially appreciative of my sister, Hilary Clemons, for flying from Nevada to surprise me and support me during my thesis defense. 


\section{Efficacy of Self-Directed Exposure Using Smart Phone Technology:}

First versus Third Person Perspective

Phobias are debilitating disorders with a high prevalence rate, and exposure therapy has been shown to be the most common and effective choice for their treatment (Wolitzky-Taylor, Horowitz, Powers, \& Telch, 2008). Many types of exposure methods have been developed, including self-directed exposure. The process of self-directed exposure involves a patient experiencing phobic material in order to produce therapeutic change, without the direction of a therapist (Michelson, Mavissakalian, Marchione, Dancu, \& Greenwald, 1986). There have been great strides in the use of self-directed exposure (Fritzler, Hecker, \& Losee, 1997), however, there still is a need to examine ways to increase adherence to treatment. A possible solution to the adherence issue is using smartphones to present phobic stimuli because of the increased norm of owning a smartphone across many segments of the population (ITU World Telecommunication ICT, 2014). To increase access to and use of self-directed exposure, it is important to examine how smartphones can be utilized to conduct exposure. The literature shows the efficacy of self-directed therapy in treating specific phobia (Michelson et al., 1986; Schneider, Mataix-Cols, Marks, \& Bachofen, 2005). Dental care-related phobia is a good exemplar for other specific phobias because of high prevalence rates and similar avoidant behaviors, which can potentially be treated through self-directed exposure with smartphones.

\section{Phobic Disorders}

The Diagnostic and Statistical Manual of Mental Disorders, $5^{\text {th }}$ edition (DSM-5) classifies specific phobia as an experience of fear in the presence of a particular stimulus, worry of encountering the feared object, and hindering the ability to function on a daily basis (American Psychiatric Association, 2013). Specific phobias have a prevalence rate of 8.7 
percent, and over 20 percent of those with a specific phobia are considered in the severe category (Kessler et al., 2005). The lifetime prevalence rate of developing a specific phobia is 12.5 percent (Craske, 2003). Dental care-related anxiety, an exemplar of specific phobia, has a prevalence rate of 10-20 percent (Smith \& Heaton, 2003). Specific phobias, thus, can be seen as a problem within the population, and examining ways to treat patients suffering from phobias has public health significance.

Fear and anxiety are associated with phobias, however, they are distinct concepts from one another, and from phobia. The fear response is an immediate reaction to the experience of a threat, which often involves visceral arousal (Craske, 2003). Frequently associated with the fear reaction is the fight or flight response of the sympathetic nervous system (SNS), which is the body's response to a perceived threat (Suresh, Latha, Nair, \& Radhika, 2014). The purpose of SNS activation is to increase alertness and reactivity to a threatening event (Rosen \& Schulkin, 1998). Anxiety, on the other hand, is defined as persistent worry and avoidant behaviors to an imminent threat (American Psychiatric Association, 2013). The fear of future threat, or anxiety, can be developed through conditioning and avoidance; traumatic experiences in relation to an object or setting can lead to developing worry and avoidance of that situation (Bouton, 2007). Anxiety and fear are connected but separate constructs, although, they will be treated as one for the purpose of this study. Using the terms fear and anxiety together makes discussion more parsimonious, and allows for the use of contemporary assessment instruments (i.e., Dental Fear Survey).

\section{Treatment of Phobias}

Exposure therapy is defined by a patient purposely coming in contact with a feared object or situation in order to generate therapeutic change (Foa \& Kozak, 1986). The process of 
exposure therapy is to challenge a previously feared object/situation by integrating new, less threatening, learning about the feared object/situation into the patients' memory (Craske et al., 2008). The new learning, thus, offers evidence against feared results when in contact with phobic stimuli (Kaplan \& Tolin, 2011). Prolonged exposure with the phobic stimuli is to cause a decrease in bodily response, or also known as habituation (Groves \& Thompson, 1970). Past literature shows that exposure therapy is efficacious in the treatment of specific phobias (Ghosh, Marks, \& Carr, 1984; Haukebø et al., 2008; Solomon, Kamin, \& Wynne, 1953). A metaanalysis conducted by Wolitzky-Taylor et al. (2008) showed that exposure therapy was effective with the treatment of many specific phobias (e.g., snakes, dogs, balloons, heights, dental).

The effectiveness of exposure therapy is attributed to facing a feared object or situation, which could create an issue with treatment adherence (Follette \& Smith, 2005). Kobak, Greist, Jefferson, Katzelnick, and Henk (1998) found that exposure treatment for obsessive-compulsive disorder had a dropout rate of 17 percent. Daflos and Whittal (2012) state that up to 25 percent of phobic patients in randomized controlled trials refuse treatment after learning it is exposure therapy. The dropout rate for treatment of specific phobia has been shown to be as much as 45 percent, furthermore, the highest rates of dropouts are those with dental phobia (Choy, Fyer, \& Lipsit, 2007). Despite high rates of non-adherence to exposure therapy, it is considered the leading choice for treatment of anxiety disorders (Wolitzky-Taylor et al., 2008). Nevertheless, it is important to examine ways to increase adherence with exposure treatment. Smartphones provide one such opportunity to increase adherence of self-directed exposure therapy.

\section{Mechanisms Involved in Exposure}

The goal of exposure therapy is for a patient to stop negative reactions to a feared object or situation, which according to Pavlov (1927) is termed extinction. An additional goal of 
exposure therapy is the development of incompatible, positive responses. Phobias can result when an originally neutral stimulus (e.g., dental drill sound) is paired with an unconditioned stimulus (e.g., pain from the drill), which causes an unconditioned response (e.g., high arousal; McNeil, Kyle, \& Nurius, 2012). After many pairings, the neutral stimulus will become a conditioned stimulus and produce a conditioned response (i.e., seeing a dental drill causes high arousal; McNeil et al., 2012). Extinction occurs when the conditioned stimulus no longer produces the conditioned response (Herry et al., 2010). Exposure therapy applies this theory by having the patient interact with the feared object or situation in a controlled and nonthreatening environment, which will result in a decrease of the conditioned response (Urcelay, 2012). Exposure therapy can lead to habituation through repeated and prolonged interactions with phobic material through the process of extinction learning (Craske, Treanor, Conway, Zbozinek, \& Vervliet, 2014). Emotional processing theory is based on the concept of habituation by Groves and Thompson (1970) and the theory of corrective learning (Rachman, 1980). There are two conditions that must be met for a decrease in fear through emotional processing. First, the fear-related stimulus is presented and activates the fear-structure. Second, the new information presented must be incompatible with information in the fear structure (Foa \& Kozak, 1986). Lang (1971) states that the fear structure is the mental representation of a stimulus (e.g., dental chair), an individual's response (e.g., elevated heart rate), and the associated meaning (e.g., I will be in pain) that exist in the individual's memory. Corrected learning takes place when the fear structure is activated and memories are created that are in conflict with the existing fear structure (Foa \& Kozak, 1986). During exposure, it is important to increase the patient's ability to violate expectancies of the situation, which can result in longer lasting change (Craske et al., 2014). Lang (1984) states that even a degraded stimulus (e.g., a 
film instead of the actual feared stimulus) can activate the emotional response by matching information with the individual's prototype of the fear. Despite the method of presenting phobic stimuli (e.g., in vivo, imagined, or filmed), the fear structure is activated and leads to a similar reaction (Lang, Levin, Miller, \& Kozak, 1983). Sufficient exposure, with corrective memories, can produce within-session habituation and between-session habituation (Craske et al., 2008). Within-session habituation is the decrease in arousal from the start and the end of an exposure session, and within-session habituation is necessary for a decrease of arousal over several exposure sessions (i.e., between-sessions habituation; Craske et al., 2008). Through the process of habituation, the decline of a conditioned fear in the presence of a feared stimulus (i.e., extinction) is the desired result with conducting exposure therapy (Myers \& Davis, 2007).

\section{Realism as a Factor in Exposure}

The literature shows that when exposure material is more realistic, it increases the likelihood of increased arousal, and bolster the effectiveness of exposure therapy (Gorini, Griez, Petrova, \& Riva, 2010). Gorini et al. (2010) found that patients with an eating disorder had increased anxiety when viewing real food and virtual food (e.g., video) than pictures of food. Kwon, Powell, and Chalmers (2013) found that realism of an interviewer (e.g., real-life recording versus cartoon version) did not increase arousal when the participants were being interviewed for a fictitious job. Reasons for the conflicting results could be that the sample was comprised of students rather than a clinical sample, and it is possible that specific fears differ than a fear of evaluation (Kwon et al., 2013).

Level of realism can affect patient arousal within exposure sessions, and one aspect to consider when using filmed exposure stimuli is video perspective (Lombard \& Ditton, 1997). Virtual reality studies have examined first- versus third-person perspective in filmed content, and 
have demonstrated the interaction of perspective and level of presence in relation to vividness of the filmed material. Presence is known as experiencing the virtual environment as real without recognizing that it is augmented, and in return participants with high rates of presence report the virtual environment as more lifelike than those with low levels of presence (Slater \& Wilbur, 1997). A meta-analysis conducted by Ling, Nefs, Morina, Heynderickx, and Brinkman (2014) showed a large effect when examining the association of presence and anxiety related to specific phobia (Slater \& Wilbur, 1997). First-person perspective has been shown to increase presence over third-person perspective in regard to video content (Dahlquist, Herbert, Weiss, \& Jimeno, 2010; Kallinen, Salminen, Ravaja, Kedzior, \& Sääksjärvi, 2007). Exposure therapy can be influenced by the vividness of filmed content, and as discussed, presence can impact the level of realism.

\section{Self-Directed Exposure}

Self-directed techniques can be utilized in the treatment of many anxiety disorders (Hellström \& Öst, 1995; Michelson et al., 1986; Schneider et al., 2005). In contrast to exposure therapy with a therapist, self-directed exposure is performed on the patient's own time and can be conducted at a time that is most convenient. Moss and Arend (1977) found that self-directed exposure was as effective in the treatment of a snake phobia as therapist guided-exposure. In contrast to these findings, a meta-analysis conducted by Abramowitz (1996) show there was greater improvement in OCD symptoms when exposure was therapist-guided than when doing self-directed exposure for homework. When patients are using self-directed therapy, they might end the exposure prematurely, thus, not allowing extinction to take place (Abramowitz, 1996). When self-directed exposure therapy is adhered to fully, the self-report of patients reflect greater improvement and continued progress than therapist guided-exposure (Baker, Cohen, \& Saunders, 
1973). The positive outcomes with using self-directed exposure could be that the patient feels confident about the ability to manage symptoms without the need of a therapist (Abramowitz \& Houts, 2005).

The effectiveness of self-directed therapy is influenced by adherence (Gould \& Clum, 1993), which may be improved with the recent increase in accessibility of self-directed therapy. The availability of self-directed therapy has increased with the use of the internet, and many websites are available to self-treat disorders (Griffiths \& Christensen, 2006). Even with the increased accessibility of internet based treatments, there is an issue of adherence (Christensen, Griffiths, \& Farrer, 2009). Common issues for dropping out of internet-based treatment are related to the website itself, such as difficulty in using it and the lack of time to access it (Andersson \& Perris, 2000; Lange et al., 2003). Over the past decade, there has been an increase in the rate and knowledge of using smartphones (Hassanein, Ali, \& Taha, 2011), which means that smartphones could be employed to increase the rates of self-directed exposure. In the year 2013, there were 6.8 billion mobile phone subscriptions worldwide, which is almost as many subscriptions as the number of people in the global population (ITU World Telecommunication ICT, 2014). For these reasons, there is a need to examine how utilizing smartphones may be a way to increase adherence with self-directed exposure.

\section{Statement of the Problem}

Previous research has demonstrated the efficacy and effectiveness of exposure therapy, including self-directed exposure, for phobias and other anxiety disorders (Hellström \& Öst, 1995; Michelson et al., 1986; Schneider et al., 2005). The efficacy of self-directed exposure, however, is dependent in part on patient adherence. Various forms of exposure stimuli are available to make it possible for patients to conduct self-directed exposure, and filmed exposure 
scenarios are commonplace (Berggren \& Carlsson, 1984). The literature on self-directed exposure has limited information on how to increase adherence (Christensen et al., 2009). Technological advancements and integration of mobile devices into daily life (Prensky, 2001), such as the ability to play videos from the internet, offer possibilities to increase adherence with self-directed exposure. Smartphones can allow patients another medium for viewing exposure material. The accessibility of exposure-related stimuli available on a smartphone has not been examined in relation to treatment progress or adherence to self-directed exposure, and assessing the utility of this technology in anxiety treatment is needed.

The level of realism in exposure stimuli can affect treatment of anxiety disorders; more realistic film, for example, will increase the effectiveness of the treatment (Gorini et al., 2010). One important aspect to increase the realistic quality in filmed exposure stimuli is the perspective of the video (Lombard \& Ditton, 1997). Virtual reality studies have examined presence, which reflects the degree an individual reports being part of the virtual environment (Slater \& Wilbur, 1997). Increased presence has been shown to cause participants to rate the virtual environment as more lifelike (Slater \& Wilbur, 1997). First-person perspective has been shown to increase presence over third-person perspective (Dahlquist et al., 2010; Kallinen et al., 2007). The literature, however, is sparse on comparing first- and third-person perspectives of videos displaying exposure material, so comparisons between them are needed.

\section{Research Questions and Hypotheses}

This study examined whether phobic individuals would use a smartphone in self-directed exposure therapy. A second issue was whether phobic participants would find the use of a smartphone an acceptable means of conducting self-directed exposure therapy. 
Accompanying these two research questions were additional specific hypotheses. The first hypothesis was that filmed exposure stimuli, available on a smartphone, would be associated with greater fear reduction in a self-directed exposure group relative to a control group. The second hypothesis was that greater presence would be reported with first-person perspective versus third-person perspective.

\section{Method}

\section{Experimental Design}

A two-group by two-assessment mixed prospective design was used. Participants were randomly assigned to group, and to the order within condition for the treatment group. See Figure 1 for a flowchart of the study.

\section{Participants}

G*Power 3, a power analysis program, developed by Faul, Erdfelder, Lang, and Buchner (2007), was used to determine sample size. In order to achieve a power of $\varphi=.80$ with two measurements and two groups at a medium effect size of .25 , the analysis suggested a total sample size of at least 34 participants (i.e., 17 in the treatment condition and 17 in control condition). Inclusion for participation included fluency in the English language, being 18 years of age or older, own or have access to a smartphone, and reported discomfort with dental-related care (i.e., at least a rating of "somewhat" on a single-item dental fear question). Participants received a compensation of $\$ 40.00$ upon completion of the study. This study adhered to the guidelines from the American Psychological Association for treatment of human research participants. In order to participate, subjects were required to sign an informed consent statement that was approved by the West Virginia University Institutional Review Board.

\section{Apparatus}


Physiological data acquisition. A computer installed with DATAQ data acquisition recording software controlled a Coulbourn Instrument no. S75-01 High Gain Bioamplifier/Coupler in order to filter and amplify electrocardiogram (ECG) data, which was used to obtain heart-rate. A Schmitt trigger apparatus, including a \#551-12 Dual Retriggerable One-Shot and CI \#S21-06 Bipolar Comparator, was used to detect an R wave during recording of ECG data. Participants had three Ag/AgCI electrodes attached: one below the right clavicle, one below the left clavicle, and one on the left torso (i.e., below the rib cage) as a ground. The electrodes were equipped with adhesive collars and were filled with a $\mathrm{NaCI} .05$ molar solution. Beats per minute $(\mathrm{bpm})$ were transformed from the recorded interbeat intervals. Heart rate was analyzed via the computer program Kubios HRV analysis package 2.0 (Tarvainen, Niskanen, Lipponen, Ranta-aho, \& Karjalainen, 2014).

Access to exposure materials. The self-directed exposure videos were provided to the participants in the treatment condition via Qualtrics, which is an online website designed to conduct research. Qualtrics is available to use on smartphones, which was utilized by the researchers. Before and after each exposure video, the participants rated distress on a Subjective Units of Distress Scale (SUDS; Wolpe, 1973). Participants completed the SUDS on their smartphones when they accessed the Qualtrics website. The SUDS rating and participants' total time spent on each webpage were collected and stored on Qualtrics, which was available for the researcher to download at a later time. Participants received one email each day at 9:00 am as a reminder to conduct the exposure session.

\section{Self-Report Measures}

Demographic and general dental information questionnaire. See Appendix A for specific questions related to demographics and general dental information. The questionnaire 
consisted of 20-items about the participants' age, sex, ethnicity, yearly income, education, employment status, transportation for dental care, and dental-related experiences.

\section{Anxiety and Related Disorders Interview Schedule for DSM-5-Adult Version}

(ADIS-5). The ADIS-5 is a structured interview conducted by trained professionals that diagnose current DSM-5 anxiety disorders, however, only the specific phobia section was used in the study. Previous versions (i.e., ADIS, ADIS-R, \& ADIS-IV) have demonstrated good psychometric properties (Brown, Di Nardo, Lehman, \& Campbell, 2001; Di Nardo, Moras, Barlow, Rapee, \& Brown, 1993). For the current study, The ADIS-5 was conducted by a trained Clinical Psychology doctoral student, and was used to describe the study's sample.

Subjective Units of Distress Scale (SUDS; Wolpe, 1973). The SUDS is a visual analog scale in which the participants rate their anxiety/fear based on a range between 0 (no anxiety/fear) and 100 (very severe anxiety/fear). Refer to Appendix B. A SUDS rating was collected at the end of each exposure video during the treatment, reflecting maximum distress experienced during the viewing. Also, SUDS were collected during each step of a behavioral avoidance task. An average of maximum distress ratings across the nine behavioral avoidance task steps was calculated for analyses.

\section{Dental Fear Survey (DFS; Kleinknecht, Klepac, \& Alexander, 1973). The DFS} consists of 20 self-report items that measure anxiety and fear in regard to dental situations. Refer to Appendix C. The measure contains three subscales and examines physiological and behavioral responses to specific dental circumstances and situations. The subscales assess dental avoidance and anxiety, fear of dental stimuli/procedures, and arousal associated with dental treatment. The DFS is rated on a 5-point Likert-type scale assessing how much of the responses (i.e., behavioral \& physiological) occur in dental situations or the level of anxiety felt within the 
specific situations. The DFS has a total score range of 20 to 100, with higher scores reflecting more dental care-related anxiety and fear (Kleinknecht et al., 1973).

DFS scores reflect general dental care-related fear and anxiety. The DFS has been widely utilized in behavioral dentistry research due to low demand on the participant in regard to time and cognitive requirements (McNeil \& Randall, 2014). The specific situations allow for individually measuring the participants' dental care-related fears. Furthermore, the DFS has demonstrated reliability (test-retest $r=.88)$ and validity $(\alpha=.95$; McGlynn, McNeil, Gallagher, \& Vrana, 1987; Smith \& Moore, 1995; Heaton, Carlson, Smith, Baer, \& Leeuw, 2007).

\section{IGroup Presence Questionnaire (IPQ; Schubert, Friedmann, \& Regenbrecht, 2001).} The IPQ is a 13-item questionnaire that measures the subjective report of presence within a virtual environment. Refer to Appendix D. Three subscales make up the IPQ: Spatial Presence, Involvement, and Realness. The IPQ is rated on a Likert-type scale ranging from 0 to 6 , and contain a variety of anchors (e.g., fully disagree to fully agree, not at all to very much). Psychometrics for the IPQ have been demonstrated to be sound, and the factor structure, has been replicated in various samples (Schubert et al., 2001).

\section{Abbreviated Acceptability Rating Profile (AARP; Tarnowski \& Simonian, 1992).}

The AARP consists of 8-items that assess acceptability of treatment. Refer to Appendix E. Items are rated on a 6-point Likert-type scale ranging from 1 (strongly disagree) to 6 (strongly agree). Good psychometrics have been demonstrated with the AARP (Cronbach's alpha ranging from .93 to .97; Caporino \& Karver, 2012; Tarnowski \& Simonian, 1992). The AARP reflected the study's treatment (e.g., "The treatment should be effective in changing [my] dental fear").

\section{Dental Behavior Avoidance Test (DBAT)}


In a laboratory furnished to simulate a dental operatory (e.g., including a dental chair), the DBAT was conducted, consistent with prior research by McNeil, McGlynn, Cassisi, and Vrana (1989). The DBAT consisted of nine steps that simulated a dental examination, and each step lasted 30 seconds. Refer to Appendix F. Escape from, or avoidance of, each step was allowed, and constituted as a measure of escape/avoidance (i.e., total number of steps escaped/avoided). A trained male research assistant portrayed the dentist. A SUDS rating was reported by the participants during each step of the DBAT. Throughout the procedure, participants' heart rate was measured using a computer that controlled a Coulbourn Instruments apparatus to measure ECG data. A one-minute baseline was recorded prior to the start of the DBAT and after completing the DBAT. Also, heart rate was measured during each step of the DBAT. A change heart rate score was calculated at each step of the DBAT, subtracting the prebaseline from the step. An average of change scores was used in analyses.

\section{Procedure}

The participants in the study were recruited through advertisements in local newspapers, posted flyers on the campus of West Virginia University, and advertised on Craigslist (e.g., a website that offers employment/services/goods). Upon arrival to the laboratory where the study was conducted, participants were given a written informed consent form and information on study procedures. The researchers discussed the procedure of the study and what was expected of the participant. The participants were informed that a $\$ 40.00$ gift card would be received for compensation at the completion of the study. After written agreement to enlist in the study, participants were randomly assigned to group (i.e., treatment or control) by previously prepared sealed opaque envelopes, then completed the demographic questionnaire, answered questions on the DFS, and completed the ADIS-5. 
Participants then participated in the DBAT, which was initiated with a one-minute baseline in the interview room, in which the participant sat quietly. The following nine steps in the DBAT each lasted 30 seconds, and a SUDS rating was collected at each step. 1. After the pre-baseline, participants moved to the simulated dental operatory and sat in a dental chair. 2 . Then a "dentist" entered the room and placed a bib and eyewear on the participants. 3 . The dentist then examined the participants" "dental chart." 4. Next, the participants were shown a typical syringe used in dental practice. 5. Following the syringe, participants listened to a dental drill. 6. Then, the dentist put on gloves, a mask, and eyewear. 7. Participants were laid back in the dental chair and the overhead light was moved to illuminate their mouth. 8 . The dentist then asked for the participants to open their mouth and made notes in their "dental chart." 9. In the final step, the dentist used a sterile tongue depressor to touch the lingual surface of the two most posterior maxillary and mandibular teeth. Thereafter, the dentist sat the participants back up to a sitting position, removed the bib and eyewear, and then the participants had a one-minute postbaseline in which they sat quietly.

After participants completed the DBAT, the researchers provided a 15-minute demonstration to the participants. The control group watched a video on their smartphone about smartphone capabilities as an attention control. The treatment group was shown how to conduct self-directed exposure therapy and rate SUDS on their smartphone. The researcher modeled how to rate SUDS prior to watching the exposure video, how to access the exposure video, how to rate actual SUDS experienced during the video, and how to either continue to the next video or stop the exposure session. After the researcher modeled the steps to conduct the self-directed exposure, the participants in the treatment condition completed the first self-directed exposure on their own, while still in the laboratory. The researcher advised that watching the exposure 
video three times per day is the ideal. Three daily video exposures were chosen as the ideal because total exposure time would equal roughly 35 minutes, which may match the amount of exposure in a typical 50-minute treatment session. The researcher advised that watching the exposure video one time per day was the suggested minimum, and viewing the exposure video five times per day was the suggested maximum. Five video exposures per day was chosen as the maximum to avoid any participant obsessively viewing the videotapes, which perhaps could lead to sensitization.

The video displayed a typical preventive visit to the dentist, including walking into the dental office, being called back for treatment by the dental assistant, sitting in the dental chair, and seeing the hygienist perform a teeth cleaning. The video was presented to the treatment group and consisted of two different versions (i.e., first- and third-person perspective), but the content of the video was identical for each version. The first-person perspective video was 11 minutes and 37 seconds long. The third-person perspective video was 11 minutes and 11 seconds long. The "patient" actor in the video was a confederate from the West Virginia University Department of Psychology who had knowledge about the purpose of the video. The providers in the video included a licensed faculty dentist and licensed dental hygienist.

Participants in the treatment group received daily emails at 9:00am as a reminder to conduct the self-directed exposure. Participants were asked to follow the link each day with their smartphones. Before each exposure video, the participants rated expected distress on the SUDS. Then the participants were asked to watch a video depicting dental care-related material. After viewing the exposure video, participants rated actual distress experienced on the SUDS. The participants were then immediately prompted to watch the video again. If the participant viewed the video again, he or she went through the same procedure of pre-rating anxiety, watching the 
video, and post-rating anxiety. Finally, the participants were prompted to complete the procedure a third time. After completing the procedure three times, the participants were no longer prompted, however, they had the ability to complete the procedure up to two more times if they so desired.

The participants in the treatment group were randomly assigned at the pre-assessment by previously-prepared sealed opaque envelopes to initial video content (i.e., first- or third-person perspective). After one week of first or third video perspective, the participants were assessed by the researcher via telephone. Questions on the IPQ and the DFS were answered by the participants. After the assessment, participants in the first-person perspective were informed that the video content would change to third-person perspective. Participants in the third-person condition were informed that the video content would change to first-person perspective. At the end of the two weeks, participants returned for an in-person follow-up and received $\$ 40.00$ compensation. The follow-up assessment consisted of the DBAT, completing the DFS, answering the IPQ, and rating acceptability of using a smartphone as a mean of self-directed exposure via the AARP.

The control group was assessed after one week via telephone and completed the DFS. After two weeks, participants in the control group were asked to return for a follow-up in-person assessment and received $\$ 40.00$ compensation. The assessment was the same as the treatment group. At the follow-up session, participants in the control group were offered the same treatment, for ethical reasons, as the experimental group; however, these data were not analyzed Overall, participants participated in two assessments in person and one assessment over the phone. Refer to Table 1 for the procedure at each assessment period.

\section{Statistical Analyses}


In order to investigate the study's first question, rate of procedure adherence was assessed to examine whether phobic individuals would use a smartphone in self-directed exposure therapy. The second question was assessed by examining participants' rating of acceptability on the AARP with using a smartphone as a method for self-directed exposure.

A 2 (treatment vs. control) x 2 (pre- vs. post-assessment) mixed measures analyses of variance (ANOVAs) was conducted to assess the first hypothesis regarding treatment effectiveness, with the DFS, and various DBAT measures (i.e., SUDS verbal reports, avoidance/escape, and cardiac response) as dependent variables. Sensitivity analyses were conducted for baseline measurements. In order to examine the second hypothesis, a paired sample $t$-test was used to assess the relation of video perspective and scores on the IPQ.

\section{Results}

A total of 37 individuals participated in the study. According to the ADIS-5, there were 20 participants who met criteria for a diagnosis of specific dental phobia (9 in the treatment condition). Of the 37 participants, one individual did not meet criteria for inclusion (i.e., due to low level of dental discomfort) and was removed from all analyses. Due to mechanical malfunctions, five participants did not have heart rate recorded during the DBAT at either pre- or post-assessment; thus, they are not included in the heart rate analysis. Refer to Table 2 for demographic characteristics of the 36 participants included in the analyses.

Participants in the control condition were offered the treatment used in the study (i.e., exposure videos viewed on their smartphone). Of the 18 participants in the control group, 6 opted for the treatment and 12 declined. Analyses were performed to assess possible baseline differences among the treatment and control conditions. Independent sample $t$-tests indicated no 
significant differences between treatment and control conditions among baseline measures at pre-assessment. Refer to Table 3 for means and results of analyses for these measures.

\section{Question 1}

It was assessed whether phobic individuals would use a smartphone in self-directed exposure therapy. Of the 18 participants in the intervention group, all of them used the smart phone at least two times during the two treatment weeks, with a range of 2 to $39(M=21.11, S D$ $=11.69)$ total times. The average number of uses per day was $1.51(S D=.84)$. A one-sample $t$ test was used to determine that the average number of videos watched daily was significantly different than $0, t(17)=7.67, p<.001$.

\section{Question 2}

It was assessed if participants found the use of a smartphone as an acceptable means of conducting self-directed exposure therapy. The AARP total score had a mean of $37.67(S D=$ 6.18), with a range from 22 to 46 . A one-sample $t$-test was used to assess if the sample scored higher than a 24, which corresponds to a total score of "Somewhat Disagree" for all eight items. Participants significantly scored higher on the AARP than a score representing somewhat disagree, $t(17)=9.37, p<.001$.

\section{Hypothesis 1}

The first hypothesis was that filmed exposure stimuli, available on a smartphone, would be associated with greater fear reduction in a self-directed exposure group relative to a control group. Fear was assessed by self-report on the DFS and components in the behavior test.

Self-report questionnaires. Analysis indicated a significant main effect for time, $F(1$, $34)=32.56, p<.001$ partial eta ${ }^{2}=.489$, such that post-assessment scores were lower $(M=64.94$, $S D=15.56)$ than pre-assessment scores on the DFS $(M=73.56, S D=11.04)$. Results reflected 
no significant main effect for condition, $F(1,34)=1.0, p=.76$. Analysis indicated the interaction between time and condition was not significant, $F(1,34)=.92, p=.35$.

Behavior assessment. Participants rated SUDS during each step of the behavioral assessment, and the average of all the steps was used in the analysis. Results indicated a significant main effect for time $F(1,34)=26.64, p<.001$ partial eta $^{2}=.439$, such that postassessment SUDS ratings $(M=38.59, S D=23.15)$ were lower than pre-assessment SUDS ratings $(M=51.12, S D=20.73)$. Analysis reflected no significant main effect for condition, $F(1$, $34)=.56, p=.46$. A significant interaction between SUDS rating and condition was found, $F(1$, $34)=8.08, p=.008$ partial eta ${ }^{2}=.192$. Refer to Figure 2 for graph of the interaction.

Avoidance, discontinuing or preventing any of the step in the behavioral assessment, was measured during the DBAT. Out of the 36 participants, only 5 escaped from any step in the DBAT (i.e., 3 in control and 2 in treatment) during the pre-assessment. Of the 5 that escaped during the pre-assessment, 4 escaped (i.e., 3 in control and 1 in treatment) at the post-assessment. No others escaped during the post-assessment. Refer to Table 4 for the specific changes from pre- to post-assessment.

Physiological reactivity. Participants' heart rate was collected during each step of the behavioral assessment, and a change score was created by subtracting the heart rate for the step from the pre-baseline. The average change score of all the steps was used in the analysis. No significant main effect for time was found $F(1,29)=2.41, p=.13$. The main effect for condition was not significant, $F(1,29)=.05, p=.83$. The interaction between time and condition was not significant, $F(1,29)=2.36, p=.14$.

\section{Hypothesis 2}


A paired-sample $t$-test was used to assess the second hypothesis, specifically level of presence experienced in first- and third-person perspective video content. The IPQ total score for the first-person perspective had a range from 16 to 69 . For the third-person perspective, the IPQ total score had a range from 15 to 64 . Analysis indicated that the first-person perspective video content $(M=39.67, S D=12.06)$ was associated with higher levels of presence when compared to the third-person perspective video content $(M=33.50, S D=12.72), t(17)=2.68, p$ $=.016$.

\section{Discussion}

No studies have examined the use of smartphone technology to present stimuli to individuals conducting self-directed exposure therapy for dental phobia. The current study assessed if participants would find the use of smartphones an acceptable medium to conduct selfdirected exposure therapy, which was supported by scores on the AARP. Furthermore, all participants in the treatment condition conducted at least two exposure sessions, and half of the participants in the treatment condition conducted at least 16 exposure sessions over the two weeks. Overall, the average number of daily exposure sessions was greater than one. Past studies suggest greater patient treatment acceptability when stimuli are augmented (e. g., on a smartphone) than presented in-person (de Carvalho, Freire, \& Nardi, 2010; Garcia-Palacios et al., 2007).

In addition to participants finding the treatment acceptable, there was support for the first hypothesis, which suggested that the treatment would be associated with a decrease in anxiety/fear at the end of treatment compared to the control condition. Participants in the treatment condition reported significantly lower levels of anxiety ratings than the control group during the DBAT at the post-assessment. No differences were found from pre- to post- 
assessment for the control condition. All participants rated lower anxiety at the post-assessment during the DBAT compared to pre-assessment anxiety ratings. The lower anxiety scores at postassessment may suggest that the DBAT acted as an exposure for the participants, thus, caused lower scores at the follow-up. Despite the decrease in anxiety ratings from pre- to postassessment for all participants, the time effect is qualified by an interaction of time by condition. Thus, results indicate that the treatment was effective in decreasing self-reported anxiety levels during a simulated dental experience. Findings are similar to many other studies examining exposure treatment for specific phobias, such that exposure treatment is associated with decreased anxiety and avoidance (Choy et al., 2007).

Significant differences from pre- to post-assessment for trait anxiety was found, such that participants scored significantly lower on the DFS at the post-assessment when compared to the pre-assessment. The findings may further indicate that the behavioral assessment acted as an exposure session for the participants. Haukebø et al. (2008) found a decrease in reported anxiety with a one-session exposure for dental phobia compared to a waitlist control. Surprisingly, the treatment group did not have even lower levels of trait anxiety than the control group at postassessment. However, the results may not be all that surprising since the DFS is based on the individual's history of dental experiences (e. g., "have you ever canceled a dental appointment"), and measures trait anxiety; whereas, the behavioral assessment, found to show the treatment effect, measures current or state anxiety.

Heart rate during the DBAT did not differ when comparing pre- and post-assessment. Also, heart rate did not differ between the treatment and control group. The results highlight how nuanced heart rate can be when used as an indicator for anxiety or fear. It is possible that averaging heart rate over the course of the behavioral assessment resulted in suppressing higher 
reactivity during a specific step of the DBAT, and not accurately showing differences between the treatment and control group at post-assessment.

Lastly, results indicate that first- versus third-person video perspective led to differences in the level of presence reported. Specifically, results support the second hypothesis, such that higher levels of presence were found when watching the first-person perspective video than the third-person perspective video. The link between more presence felt while watching a firstperson perspective video over a third-person perspective video has been well documented (Dahlquist et al., 2010; Kallinen et al., 2007). Thus, this study further strengthens the literature comparing first-person versus third-person perspective and level of presence felt, and extends it to self-directed exposure therapy.

Findings of the study can help direct future treatment for a disorder (i.e., dental phobia) that often goes untreated. It is important to examine how technology can be incorporated into treatment to prevent high dropout rates associated with exposure therapy. Choy et al. (2007) report a dropout rate of up to 45 percent for treatment of specific phobia. In addition to possible decreased dropout rates, utilizing smartphone technology may increase adherence to treatment. Often a component for exposure therapy is to conduct self-directed exposures outside of the clinic, but patients may find it difficult to conduct exposures on their own (Leahy, Holland, \& McGinn, 2011). The results of the study suggest that treatment adherence may be improved if stimuli for exposure are presented via smartphone perhaps because of the portability it presents. Furthermore, the portability of smartphones can result in greater reach to underserved groups.

Integrating smartphones into treatment may decrease the total visits needed to treat phobia. It is possible that the treatment used in the study can be used as a stand-alone intervention as well, which means those who do not have access to mental health treatment can 
still have their dental phobia treated. Chan, Torous, Hinton, Ladson, and Yellowlees (2016) suggest there are many advantages of mental health "apps" (e.g., applications downloaded to smartphones with specific functions), such as a decrease in the cost of treatment, an increase in the portability of care, and the opportunity for real-time feedback to patients. Lastly, exposure therapy conducted on smartphones may decrease total cost of treatment due to the previous advantages (e.g., portability and decreased visits).

The study had several limitations, which present possible future directions for research. A possible limitation in the study was the video used for the self-directed exposure therapy, which depicted a typical visit to the dentist (i.e., prophylaxis or cleaning of the teeth and gums). The content may not match the anxiety or fear participants experience during dental visits (e.g., fear of the drill or worry of receiving bad news). Thus, the treatment may have only targeted state anxiety instead of the fears and trait anxiety participants experienced. Future research could focus on using videos that are directed to personalized fears and depict more intense (e.g., tooth restorations or extractions) dental visits, and assess how the intensity of the video may affect treatment outcomes.

Although steps were taken to assess how long participants in the treatment condition viewed the exposure videos on their smartphones, there is no way of knowing if the participants watched the videos vigilantly or imagined themselves as the patient due to the nature of the therapy (i.e., self-directed). Future research can explore how outcomes differ when videos are watched in and out of a lab/clinic setting. Another direction for research is to assess if differences arise from therapist-guided versus self-directed exposure with smartphones.

Generalizability of the results also may be a concern. In particular, a large proportion of the sample were White/Caucasian participants, and the results may not generalize to other 
races/ethnicities. Also, more than $50 \%$ of the sample was recruited through introductory psychology classes offered at West Virginia University, which may have influenced the results. However, participants were randomly assigned to group and there was no difference found at baseline for the measures used in the study. Future studies should attempt to recruit a more diverse sample to assess possible demographic differences. Furthermore, the study used dental phobia as an exemplar for specific phobia, and future research could adapt the study to include other forms of specific phobia.

Incorporating smartphones into exposure therapy presents a host of advantages, especially in regard to treatment of dental phobia. Technology continues to advance and is being incorporated more and more into daily life. Thus, it is important to assess how harnessing technology can improve treatment adherence and effectiveness. The study demonstrates that smartphones can be utilized as a medium to conduct self-directed exposure therapy; furthermore, participants found the treatment acceptable and rated it favorably as a means to treat their dental care-related fear and anxiety. 


\section{References}

Abramowitz, J. S. (1996). Variants of exposure and response prevention in the treatment of obsessive-compulsive disorder: A meta-analysis. Behavior Therapy, 27(4), 583-600. http://doi.org/10.1016/S0005-7894(96)80045-1

American Psychiatric Association. (2013). Diagnostic and statistical manual of mental disorders (5th ed.). Washington DC: American Psychiatric Publishing.

Andersson, P., \& Perris, C. (2000). Perceptions of parental rearing and dysfunctional attitudes: The link between early experiences and individual vulnerability? Nordic Journal of Psychiatry, 54(6), 405-409. http://doi.org/10.1080/080394800750061388

Baker, B. L., Cohen, D. C., \& Saunders, J. T. (1973). Self-directed desensitization for acrophobia. Behaviour Research and Therapy, 11(1), 79-89. http://doi.org/10.1016/00057967(73)90071-5

Berggren, U., \& Carlsson, S. G. (1984). A psychophysiological therapy for dental fear.

Behaviour Research and Therapy, 22(5), 487-492. http://doi.org/10.1016/00057967(84)90052-4

Bouton, M. E. (2007). Learning and behavior: A contemporary synthesis. Sunderland, MA: Sinauer.

Brown, T. a, Di Nardo, P. a, Lehman, C. L., \& Campbell, L. a. (2001). Reliability of DSM-IV anxiety and mood disorders: Implications for the classification of emotional disorders. Journal of Abnormal Psychology, 110(1), 49-58. http://doi.org/10.1037/0021843X.110.1.49 
Caporino, N. E., \& Karver, M. S. (2012). The acceptability of treatments for depression to a community sample of adolescent girls. Journal of Adolescence, 35(5), 1237-1245. http://doi.org/10.1016/j.adolescence.2012.04.007

Carmin, C. N., Wiegartz, P. S., \& Wu, K. D. (2005). Self-directed exposure in the treatment of OCD. In J. S. Abramowitz \& A. C. Houts (Eds.), Concepts and controversies in obsessivecompulsive disorder (pp. 333-346). Springer New York. http://doi.org/10.1007/b101087

Chan, S., Torous, J. B., Hinton, L., \& Yellowlees, P. M. (2016). Psychiatric apps: Patient selfassessment, communication, and potential treatment interventions. In D. Mucic \& D. M. Hilty (Eds.), e-Mental Health (pp. 217-229). Springer International Publishing. http://doi.org/10.1007/978-3-319-20852-7_11

Choy, Y., Fyer, A. J., \& Lipsit, J. D. (2007). Treatment of specific phobia in adults. Clinical Interventions in Aging, 17(3), 266-286. http://doi.org/10.1016/j.cpr.2006.10.002

Christensen, H., Griffiths, K. M., \& Farrer, L. (2009). Adherence in internet interventions for anxiety and depression. Journal of Medical Internet Research, 11(2), 1-23. http://doi.org/10.2196/jmir.1194

Craske, M. G. (2003). Origins of phobias and anxiety disorders: Why more women than men? Oxford, UK: Elsevier Ltd. http://doi.org/10.1016/B978-008044032-3/50005-8

Craske, M. G., Kircanski, K., Zelikowsky, M., Mystkowski, J., Chowdhury, N., \& Baker, A. (2008). Optimizing inhibitory learning during exposure therapy. Behaviour Research and Therapy, 46(1), 5-27. http://doi.org/10.1016/j.brat.2007.10.003

Craske, M. G., Treanor, M., Conway, C. C., Zbozinek, T., \& Vervliet, B. (2014). Maximizing exposure therapy: An inhibitory learning approach. Behaviour Research and Therapy, 58, 10-23. http://doi.org/10.1016/j.brat.2014.04.006 
Daflos, S., \& Whittal, M. L. (2012). Exposure therapy in OCD: Is there a need for adding cognitive elements? In P. Neudeck \& H.-U. Wittchen (Eds.), Exposure therapy: Rethinking the model-refining the method (pp. 335-350). http://doi.org/10.1007/978-1-4614-3342-2

Dahlquist, L. M., Herbert, L. J., Weiss, K. E., \& Jimeno, M. (2010). Virtual-reality distraction and cold-pressor pain tolerance: Does avatar point of view matter? Cyberpsychology, Behavior and Social Networking, 13(5), 587-91. http://doi.org/10.1089/cyber.2009.0263

Di Nardo, P., Moras, K., Barlow, D. H., Rapee, R. M., \& Brown, T. a. (1993). Reliability of DSM-III-R anxiety disorder categories. Using the Anxiety Disorders Interview ScheduleRevised (ADIS-R). Archives of General Psychiatry, 50(4), 251-256. http://doi.org/10.1001/archpsyc.1993.01820160009001

Faul, F., Erdfelder, E., Lang, A.-G., \& Buchner, A. (2007). G*Power 3: A flexible statistical power analysis program for the social, behavioral, and biomedical sciences. Behavior Research Methods, 39(2), 175-191. http://doi.org/10.3758/BF03193146

Foa, E. B., \& Kozak, M. J. (1986). Emotional processing of fear: Exposure to corrective information. Psychological Bulletin, 99(1), 20-35. http://doi.org/10.1037/00332909.99.1.20

Follette, V., \& Smith, A. (2005). Exposure therapy. In A. Freeman, S. H. Felgoise, C. M. Nezu, A. M. Nezu, \& M. A. Reinecke (Eds.), Encyclopedia of Cognitive Behavior Therapy (Vol. 19, pp. 185-88). Springer US. http://doi.org/10.1007/b99240

Fritzler, B. K., Hecker, J. E., \& Losee, M. C. (1997). Self-directed treatment with minimal therapist contact: Preliminary findings for obsessive-compulsive disorder. Behaviour Research and Therapy, 35(7), 627-631. http://doi.org/10.1016/S0005-7967(97)00024-7 
Garcia-Palacios, A., Botella, C., Hoffman, H., \& Fabregat, S. (2007). Comparing acceptance and refusal rates of virtual reality exposure vs. in vivo exposure by patients with specific phobias. Cyberpsychology \& Behavior: The Impact of the Internet, Multimedia and Virtual Reality on Behavior and Society, 10(5), 722-724. http://doi.org/10.1089/cpb.2007.9962

Ghosh, A., Marks, I. M., \& Carr, A. C. (1984). Controlled study of self-exposure treatment for phobics: Preliminary communication. Journal of the Royal Society of Medicine, 77(June), $483-487$.

Gorini, A., Griez, E., Petrova, A., \& Riva, G. (2010). Assessment of the emotional responses produced by exposure to real food, virtual food and photographs of food in patients affected by eating disorders. Annals of General Psychiatry, 9, 30. http://doi.org/10.1186/1744-859X$9-30$

Gould, R. A., \& Clum, G. A. (1993). A meta-analysis of self-help treatment approaches. Clinical Psychology Review, 13(2), 169-186. http://doi.org/10.1016/0272-7358(93)90039-O

Griffiths, K. M., \& Christensen, H. (2006). Review of randomised controlled trials of Internet interventions for mental disorders and related conditions. Clinical Psychologist, 10(1), 1629. http://doi.org/10.1080/13284200500378696

Groves, P. M., \& Thompson, R. F. (1970). Habituation: A dual-process theory. Psychological Review, 77(5), 419-450. http://doi.org/10.1037/h0029810

Hassanein, H. S., Ali, N. A., \& Taha, A. M. (2011). LTE, LTE-advanced and wimax: Towards IMT-advanced networks. John Wiley \& Sons Ltd.

Haukebø, K., Skaret, E., Ost, L., Raadal, M., Berg, E., Sundberg, H., \& Kvale, G. (2008). Onevs. five-session treatment of dental phobia: A randomized controlled study. Journal of 
Behavior Therapy and Experimental Psychiatry, 39(3), 381-90.

http://doi.org/10.1016/j.jbtep.2007.09.006

Hellström, K., \& Öst, L. G. (1995). One-session therapist directed exposure vs two forms of manual directed self-exposure in the treatment of spider phobia. Behaviour Research and Therapy, 33(8), 959-965. http://doi.org/10.1016/0005-7967(95)00028-V

Herry, C., Ferraguti, F., Singewald, N., Letzkus, J. J., Ehrlich, I., \& Lüthi, A. (2010). Neuronal circuits of fear extinction. European Journal of Neuroscience, 31(4), 599-612. http://doi.org/10.1111/j.1460-9568.2010.07101.x

ITU World Telecommunication ICT. (2014). Facts and figures. Retrieved May 4, 2015, from http://www.itu.int/en/ITU-D/Statistics/Pages/facts/default.aspx

Kallinen, K., Salminen, M., Ravaja, N., Kedzior, R., \& Sääksjärvi, M. (2007). Presence and emotion in computer game players during 1st person vs. 3rd person playing view: Evidence from self-report, eye-tracking, and facial muscle. Presence, 187-190. Retrieved from http://www.temple.edu/ispr/prev_conferences/proceedings/2007/Kallinen, et al.pdf

Kaplan, B. J. S., \& Tolin, D. F. (2011). Exposure therapy for anxiety dDisorders. Psychiatric Times, 28(9), 1-7. Retrieved from http://www.psychiatrictimes.com/anxiety/exposuretherapy-anxiety-disorders

Kessler, R. C., Berglund, P., Demler, O., Jin, R., Merikangas, K. R., \& Walters, E. E. (2005). Lifetime prevalence and age-of-onset distributions of DSM-IV disorders in the National Comorbidity Survey Replication. Archives of General Psychiatry, 62(6), 593-602. http://doi.org/10.1001/archpsyc.62.6.593 
Kleinknecht, R. A., Klepac, R. K., \& Alexander, L. D. (1973). Origins and characteristics of fear of dentistry. Journal of the American Dental Association, 86(4), 842-848. http://doi.org/10.14219/jada.archive.1973.0165

Kobak, K. A., Greist, J. H., Jefferson, J. W., Katzelnick, D. J., \& Henk, H. J. (1998). Behavioral versus pharmacological treatments of obsessive compulsive disorder: A meta-analysis. Psychopharmacology, 136(3), 205-216. http://doi.org/10.1007/s002130050558

Kwon, J. H., Powell, J., \& Chalmers, A. (2013). How level of realism influences anxiety in virtual reality environments for a job interview. International Journal of Human-Computer Studies, 71(10), 978-987. http://doi.org/10.1016/j.ijhcs.2013.07.003

Lang, P. J. (1971). The application of psychophysiological methods to the study of psychotherapy and behaviour modification. In A. E. Bergin \& S. L. Garfield (Eds.), Handbook of psychotherapy and behavior change (pp. 75-125). New York: John Wiley \& Sons.

Lang, P. J. (1984). Cognition in emotion: Concept and action. In C. E. Izard, J. Kagan, \& R. B. Zajonc (Eds.), Emotions, cognition, and behavior (pp. 192-226). Cambridge: Cambridge Univ Press Cambridge. Retrieved from www.summon.com

Lang, P. J., Levin, D. N., Miller, G. A., \& Kozak, M. J. (1983). Fear behavior, fear imagery, and the psychophysiology of emotion: The problem of affective response integration. Journal of Abnormal Psychology, 92(3), 276-306. http://doi.org/10.1037/0021-843X.92.3.276

Lange, A., Rietdijk, D., Hudcovicova, M., Van De Ven, J., Schrieken, B., \& Emmelkamp, P. M. G. (2003). Interapy: A controlled randomized trial of the standardized treatment of posttraumatic stress through the internet. Journal of Consulting and Clinical Psychology, 71(5), 901-909. http://doi.org/10.1037/0022-006X.71.5.901 
Leahy, R. L., Holland, S. J., \& McGinn, L. K. (2011). Treatment plans and interventions for depression and anxiety disorders. Guilford press.

Ling, Y., Nefs, H. T., Morina, N., Heynderickx, I., \& Brinkman, W. P. (2014). A meta-analysis on the relationship between self-reported presence and anxiety in virtual reality exposure therapy for anxiety disorders. PloS One, 9(5), e96144.

http://doi.org/10.1371/journal.pone.0096144

Lombard, M., \& Ditton, T. (1997). At the heart of it all: The concept of presence. Journal of Computer-Mediated Communication, 3(2), 20. http://doi.org/10.1111/j.10836101.1997.tb00072.x

McNeil, D. W., Kyle, B. N., \& Nurius, P. (2012). Exposure therapy and straegies. Imaginal, in vitro, in vivo, and intensive. In S. Cormier, P. Nurius, \& C. Osborn (Eds.), Interviewing and change strategies for helpers (7th ed.).

McNeil, D. W., McGlynn, F. D., Cassisi, J. E., \& Vrana, S. R. (1989). Cardiac and electrodermal reactivity in a mock dental operatory behavioral assessment test. Psychophysiology, 26, S43. [Abstract]

McNeil, D. W., \& Randall, C. L. (2014). Dental fear and anxiety associated with oral health care: Conceptual and clinical issues. In D. I. Mostofsky \& F. Fortune (Eds.), Behavioral dentistry (2nd ed., pp. 165-192). Ames, IA: Wiley/Blackwell.

Michelson, L., Mavissakalian, M., Marchione, K., Dancu, C., \& Greenwald, M. (1986). The role of self-directed in vivo exposure in cognitive, behavioral, and psychophysiological treatments of agoraphobia. Behavior Therapy, 17(2), 91-108. http://doi.org/10.1016/S00057894(86)80078-8 
Moss, M. K., \& Arend, R. A. (1977). Self-directed contact desensitization. Journal of Consulting and Clinical Psychology, 45(5), 730-738. http://doi.org/10.1037/0022-006X.45.5.730

Myers, K. M., \& Davis, M. (2007). Mechanisms of fear extinction. Molecular Psychiatry, 12(2), 120-150. http://doi.org/10.1038/sj.mp.4001939

Pavlov, I. P. (1927). Conditioned reflexes: An investigation of the physiological activity of the cerebral cortex. Oxford, UK: Oxford University Press.

Prensky, M. (2001). Digital natives, digital immigrants part 1. On the Horizon, 9(5), 1-6. http://doi.org/10.1108/10748120110424816

Rachman, S. (1980). Emotional processing. Behaviour Research and Therapy, 18(1), 51-60. http://doi.org/10.1016/0005-7967(80)90069-8

Rosen, J. B., \& Schulkin, J. (1998). From normal fear to pathological anxiety. Psychological Review, 105(2), 325-350. http://doi.org/10.1037/0033-295X.105.2.325

Schneider, A. J., Mataix-Cols, D., Marks, I. M., \& Bachofen, M. (2005). Internet-guided selfhelp with or without exposure therapy for phobic and panic disorders. Psychotherapy and Psychosomatics, 74(3), 154-64. http://doi.org/10.1159/000084000

Schubert, T., Friedmann, F., \& Regenbrecht, H. (2001). The experience of presence: Factor analytic insights. Presence: Teleoperators and Virtual Environments, 10(3), 266-281. http://doi.org/10.1162/105474601300343603

Slater, M., \& Wilbur, S. (1997). A framework for immersive virtual environments (FIVE): Speculations on the role of presence in virtual environments. Presence: Teleoperators and Virtual Environments, 6(6), 1-20. Retrieved from http://publicationslist.org/data/melslater/ref-232/pres5.pdf 
Smith, T. a, \& Heaton, L. J. (2003). Fear of dental care: Are we making any progress? Journal of the American Dental Association, 134(8), 1101-1108. http://doi.org/10.14219/jada.archive.2003.0326

Solomon, R. L., Kamin, L. J., \& Wynne, L. C. (1953). Traumatic avoidance learning: The outcomes of several extinction procedures with dogs. Journal of Abnormal Psychology, 48(2), 291-302. http://doi.org/10.1037/h0058943

Suresh, A., Latha, S. S., Nair, P., \& Radhika, N. (2014). Prediction of fight or flight response using artificial neural networks. American Journal of Applied Sciences, 11(6), 912-920. http://doi.org/10.3844/ajassp.2014.912.920

Tarnowski, K. J., \& Simonian, S. J. (1992). Assessing treatment acceptance: The abbreviated acceptability rating profile. Journal of Behavior Therapy and Experimental Psychiatry, 23(2), 101-106. http://doi.org/10.1016/0005-7916(92)90007-6

Tarvainen, M. P., Niskanen, J. P., Lipponen, J. A., Ranta-aho, P. O., \& Karjalainen, P. A. (2014). Kubios HRV - Heart rate variability analysis software. Computer Methods and Programs in Biomedicine, 113(1), 210-220. http://doi.org/10.1016/j.cmpb.2013.07.024

Urcelay, G. P. (2012). Exposure techniques: The role of extinction learning. In Exposure therapy: Rethinking the model-refining the method (pp. 35-63). New York, NY: Springer New York. http://doi.org/10.1007/978-1-4614-3342-2_4

Wolitzky-Taylor, K. B., Horowitz, J. D., Powers, M. B., \& Telch, M. J. (2008). Psychological approaches in the treatment of specific phobias: A meta-analysis. Clinical Psychology Review, 28(6), 1021-1037. http://doi.org/10.1016/j.cpr.2008.02.007

Wolpe, J. (1973). The practice of behavior therapy. New York: Pergamon Press. 
Figure 1. Flowchart for the Groups of the Study

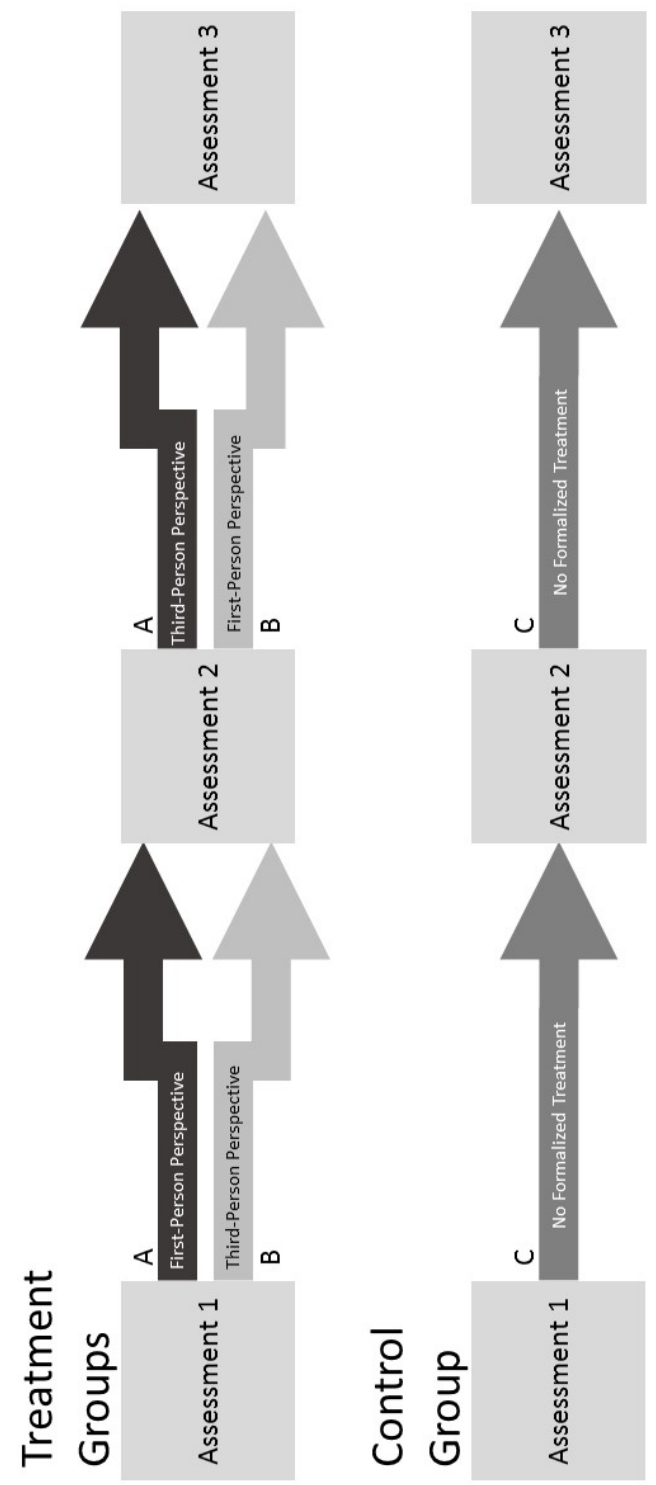

Note. Participants were randomly assigned to treatment or control group. Individuals in the treatment group were randomly assigned to video perspective condition. $\mathrm{A}=$ treatment condition that viewed first-person perspective for the first week and third-person perspective for the second week. $\mathrm{B}=$ treatment condition that viewed the third-person perspective the first week and firstperson perspective the second week. $\mathrm{C}=$ control group, which did not involve treatment. 
Figure 2. Graph of Interaction Between Pre- and Post-Assessment SUDS Rating and Condition

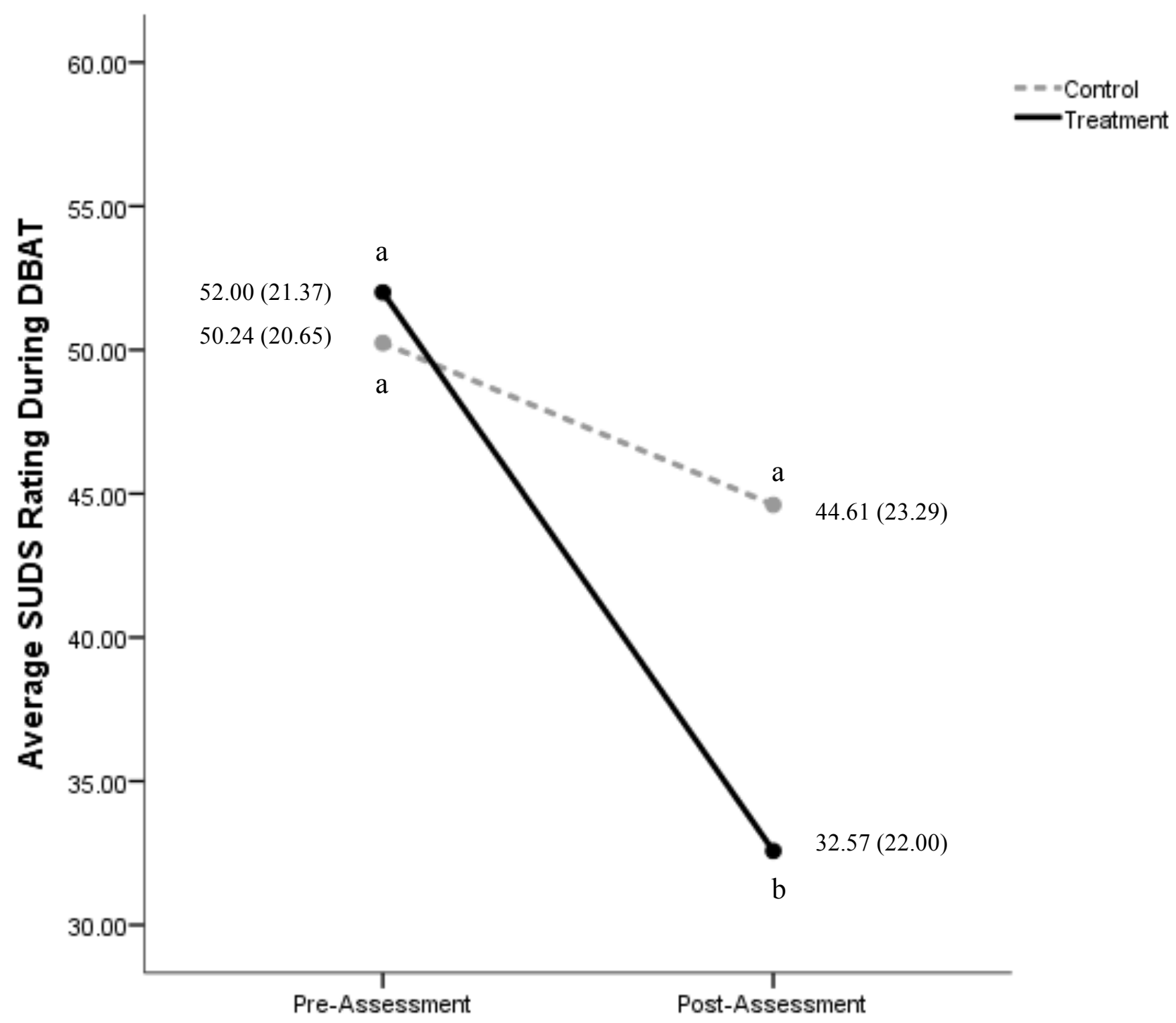

Note. Tukey’s Honest Significant Difference Test at the .05 level was ran to assess mean differences between the conditions and time points. Points that have different letters reflect a significant difference. 
Table 1.

Procedure during Assessment Periods

\begin{tabular}{|c|c|c|c|c|c|c|}
\hline & \multicolumn{2}{|c|}{ Time 1} & \multicolumn{2}{|c|}{ Time 2} & \multicolumn{2}{|c|}{ Time 3} \\
\hline & Treatment & Control & Treatment & Control & Treatment & Control \\
\hline $\begin{array}{c}\text { Data } \\
\text { Gathering }\end{array}$ & In Person & In Person & Phone & Phone & In Person & In Person \\
\hline Measures & DEM and DFS & $\begin{array}{l}\text { DEM and } \\
\text { DFS }\end{array}$ & $\begin{array}{l}\text { IPQ and } \\
\text { DFS }\end{array}$ & DFS & $\begin{array}{l}\text { DFS, IPQ, } \\
\text { and AARP }\end{array}$ & DFS \\
\hline DBAT & Yes & Yes & No & No & Yes & Yes \\
\hline Heart-Rate & Yes & Yes & No & No & Yes & Yes \\
\hline
\end{tabular}

Note. DEM = Demographics; DFS = Dental Fear Survey; IPQ = IGroup Presence Questionnaire; AARP $=$ Abbreviated Acceptability Rating Profile; DBAT $=$ Dental Behavior Avoidance Test. 
Table 2 .

Sample Demographic Characteristics

\begin{tabular}{|c|c|c|c|c|c|}
\hline$(\mathrm{N}=36)$ & $\begin{array}{l}1^{\text {st }} \text { Person } \\
\text { Perspective }\end{array}$ & $\begin{array}{l}3^{\text {rd }} \text { Person } \\
\text { Perspective }\end{array}$ & Treatment & Control & Total \\
\hline Age M (SD) & $28.6(15.4)$ & $25.2(10.5)$ & $26.9(12.9)$ & $24.1(8.3)$ & $25.5(10.8)$ \\
\hline Education in years $M(\mathrm{SD})$ & $14.1(2.2)$ & $15.3(1.9)$ & $14.7(2.1)$ & $14.3(2.3)$ & $14.5(2.2)$ \\
\hline \multicolumn{6}{|l|}{ Population } \\
\hline Student & $3(33.3)$ & $2(22.2)$ & $5(27.8)$ & $8(44.4)$ & $13(36.1)$ \\
\hline Community & $6(66.7)$ & $7(77.8)$ & $13(72.2)$ & $10(55.6)$ & $23(63.9)$ \\
\hline \multicolumn{6}{|l|}{ Gender N (\%) } \\
\hline Female & $6(66.7)$ & $5(55.6)$ & $11(61.1)$ & $11(61.1)$ & $22(61.1)$ \\
\hline Male & $3(33.3)$ & $4(44.4)$ & $7(38.9)$ & $7(38.9)$ & $14(38.9)$ \\
\hline \multicolumn{6}{|l|}{ Race/Ethnicity* N (\%) } \\
\hline White/Caucasian & $9(100)$ & $9(100)$ & $18(100)$ & $17(94.4)$ & $35(97.2)$ \\
\hline Hispanic/Spanish & & & & $1(5.6)$ & $1(2.8)$ \\
\hline Asian & & $1(11.1)$ & $1(5.6)$ & & $1(2.8)$ \\
\hline \multicolumn{6}{|l|}{ Last Dental Visit N (\%) } \\
\hline 6 months or less & $4(44.4)$ & $1(11.1)$ & $5(27.8)$ & $9(50.0)$ & $14(38.9)$ \\
\hline 6 months to 1 year & $1(11.1)$ & $4(44.4)$ & $5(27.8)$ & $5(27.8)$ & $10(27.8)$ \\
\hline $1-2$ years & $3(33.3)$ & & $3(16.7)$ & $1(5.6)$ & 4 (11.1) \\
\hline $2-5$ years & $1(11.1)$ & $3(33.3)$ & $4(22.2)$ & $1(5.6)$ & $5(13.9)$ \\
\hline $5+$ years & & $1(11.1)$ & $1(5.6)$ & $2(11.1)$ & $3(8.4)$ \\
\hline
\end{tabular}

Note. Percentages equal more than $100 \%$ due to participants choosing more than one race/ethnicity. 
Table 3.

Means of the Measures Used at Baseline for the Treatment and Control Group

\begin{tabular}{lcccc}
\hline Measure M (SD) & Treatment & Control & $t$-test statistic & $p$-value \\
\hline DFS & $73.61(10.52)$ & $73.50(11.85)$ & .03 & .98 \\
SUDS & $52.00(21.37)$ & $50.24(20.65)$ & .25 & .80 \\
HR & $72.94(13.24)$ & $76.41(13.47)$ & .72 & .48 \\
\hline
\end{tabular}

Note. DFS = Dental Fear Survey; SUDS = Subjective Units of Distress Scale; HR = Average heart rate. 
Table 4.

Number of Steps Avoided During the DBAT at Pre- and Post-Assessment

\begin{tabular}{ccccc}
\hline Participant ID & \multicolumn{2}{c}{ Treatment } & \multicolumn{2}{c}{ Control } \\
\hline & Pre-Assessment & Post-Assessment & Pre-Assessment & Post-Assessment \\
\cline { 2 - 5 } 1 & 2 & 0 & & \\
11 & 3 & 1 & 5 & 4 \\
10 & & & 4 & 4 \\
20 & & 4 & 5 \\
\hline
\end{tabular}

Note. There was a total of 9 steps in the DBAT. 


\section{Appendix A}

Demographic and General Dental Information Questionnaire

Name (print): Date:

Email address:

1. What is your gender?

2. What is your age?

3. What is your race/ethnicity? Circle all that Apply:

4. What is your marital status?

6. What is your job or occupation?

7. What is your current job or occupation status?

5. Number of years of education?

(For example, High School Diploma $=12$ years, College Degree $=16$ years)
White/Caucasian

Black/African American

Hispanic

Asian

Native American

Other:

$\begin{array}{ll}\text { Single } & \text { Separated } \\ \text { Married } & \text { Divorced } \\ \text { Live-in partner } & \text { Widowed }\end{array}$

Female years

Widowed
Working full time

Working part time

Looking for work - unemployed

Retired

Disabled - unable to work
8. How do you get to dental appointments?
Have a car/truck/vehicle that I primarily or solely use Have a car/truck/vehicle that I share with a spouse/partner Borrow a car/truck/vehicle Have a family member bring me Have a friend bring me Have a social services agency bring me Other:
9. For the vehicle that gets you to dental appointments, how reliably does it run?

$\begin{array}{lllll}0 & 1 & 2 & 3 & 4 \\ \text { Very } & & & & \begin{array}{l}\text { Very } \\ \text { Reliable }\end{array} \\ \text { Unreliable } & & & \end{array}$


10. What factors make it difficult for you to schedule or attend dental care responsibilities appointments? (circle or list all that apply)

11. How long since you last saw a dentist?

12. When you go to the dentist, what typically gets you to go?

13. Do you presently have any dental pain?

14. Have you ever had problems with gagging during dental visits?

15. If you have EVER had problems with gagging during dental visits, how severe have these problems been?

16. If you have EVER had problems with gagging during dental visits, how often as gagging interrupted the dental treatment?

Pain Other: hard to get away from work

child

transportation hard to arrange

Other:

6 months or less

6 months -1 year

$1-2$ years

$2-5$ years

$5-10$ years

More than 10 years

Never saw a dentist

Regular cleaning and exam

Seeing a cavity or another problem in my mouth

\begin{tabular}{|c|c|c|c|c|}
\hline 0 & 1 & 2 & 3 & 4 \\
\hline No Pain & & & & Severe Pain \\
\hline 0 & 1 & 2 & 3 & 4 \\
\hline Never & & & & $\begin{array}{c}\text { Almost Always } \\
\text { or Always }\end{array}$ \\
\hline 0 & 1 & 2 & 3 & 4 \\
\hline Very Milc & & & & Very Severe \\
\hline
\end{tabular}

17. What triggers your gagging during dental visits? (list ALL that apply) (For example, x-rays, impressions, fingers in your mouth, instruments in your mouth)

18. Do you have problems with gagging at times other than dental visits?

19. If you have EVER had problems with gagging at times other than dental visits, how severe have these problems been?

$\begin{array}{ccccc}0 & 1 & 2 & 3 & 4 \\ \text { Never } & & & & \begin{array}{c}\text { Almost Always } \\ \text { or Always }\end{array} \\ 0 & 1 & 2 & 3 & 4 \\ \text { Very Mild } & & & & \text { Very Severe }\end{array}$

23
Almost Always
or Always

20. What triggers your gagging at these other times? (list ALL that apply) 
Appendix B

Subjective Units of Distress Scale

Try to get used to rating your distress, fear, anxiety or discomfort on a scale of 0-100. Imagine you have a 'distress thermometer' to measure your feelings according to the following scale.

100 Highest distress/fear/anxiety/discomfort that you have ever felt

90 Extremely anxious/distressed

80 Very anxious/distressed, can't concentrate

70 Quite anxious/distressed, interfering with performance

60

50 Moderate anxiety/distress, uncomfortable but can continue to perform

40

30 Mild anxiety/distress, no interference with performance

20 Minimal anxiety/distress

10 Alert and awake, concentrating well

$0 \quad$ Totally relaxed 


\section{Appendix C}

\section{Dental Fear Survey}

INSTRUCTIONS: The items in this questionnaire refer to various situations, feelings, and reactions related to dental work. Please rate your feeling or reaction on these items by using the following scales. Fill in the appropriate circle which most closely corresponds to your reaction.

1. Has fear of dental work ever caused you to put off making an appointment?

2. Has fear of dental work ever caused you to cancel or not appear for an appointment?

\begin{tabular}{|c|c|c|c|c|}
\hline Never & $\begin{array}{c}\text { Once or } \\
\text { twice }\end{array}$ & $\begin{array}{l}\text { A few } \\
\text { times }\end{array}$ & Often & $\begin{array}{c}\text { Nearly } \\
\text { every time }\end{array}$ \\
\hline 1 & 2 & 3 & 4 & 5 \\
\hline 1 & 2 & 3 & 4 & 5 \\
\hline
\end{tabular}

When having dental work done:

3. My muscles become tense...

4. My breathing rate increases...

$\begin{array}{ccccc}\text { Not At All } & \text { A little } & \text { Somewhat } & \text { Much } & \text { Very much } \\ 1 & 2 & 3 & 4 & 5 \\ 1 & 2 & 3 & 4 & 5 \\ 1 & 2 & 3 & 4 & 5 \\ 1 & 2 & 3 & 4 & 5\end{array}$

6. I feel nauseated and sick to my stomach...

7. My heart beats faster...

12

$\begin{array}{lll}3 & 4 & 5\end{array}$

Following is a list of things, and situations that many people mention as being somewhat anxiety or fear producing. Please rate how much fear, anxiety, or unpleasantness each of them causes you. (If it helps, try to imagine yourself in each of these situations and describe what your common reaction is.)

8. Making an appointment for dentistry.

9. Approaching the dentist's office.

10. Sitting in the waiting room.

11. Being seated in the dental chair.

12. The smell of the dentist's office.

13. Seeing the dentist walk in.

14. Seeing the anesthetic needle.

15. Feeling the needle injected.

16. Seeing the drill.

17. Hearing the drill.

18. Feeling the vibrations of the drill.

19. Having your teeth cleaned.

20. All things considered, how fearful are you

$\begin{array}{ccccc}\begin{array}{c}\text { Not At } \\ \text { All }\end{array} & \begin{array}{c}\text { A } \\ \text { little }\end{array} & \text { Somewhat } & \text { Much } & \begin{array}{c}\text { Very } \\ \text { much }\end{array} \\ 1 & 2 & 3 & 4 & 5 \\ 1 & 2 & 3 & 4 & 5 \\ 1 & 2 & 3 & 4 & 5 \\ 1 & 2 & 3 & 4 & 5 \\ 1 & 2 & 3 & 4 & 5 \\ 1 & 2 & 3 & 4 & 5 \\ 1 & 2 & 3 & 4 & 5 \\ 1 & 2 & 3 & 4 & 5 \\ 1 & 2 & 3 & 4 & 5 \\ 1 & 2 & 3 & 4 & 5 \\ 1 & 2 & 3 & 4 & 5 \\ 1 & 2 & 3 & 4 & 5 \\ 1 & 2 & 3 & 4 & 5\end{array}$
of having dental work done? 


\section{Appendix D}

\section{IGroup Presence Questionnaire}

Directions: Now you will read some statements about your experiences while watching the videos over the past week. Please indicate, whether or not each statement applies to your experience. You can use the whole range of answers. There are no right or wrong answers, only your opinion counts. You may notice that some questions are very similar to each other, but please attempt to answer to the best of your ability.

\section{Please remember when answering these questions only refer to your experiences while watching the videos over the past week.}

$1 \quad$ Somehow I felt that the virtual world surrounded me.

$\begin{array}{ccccccc}0 & 1 & 2 & 3 & 4 & 5 & 6 \\ \text { Fully } & & & & & & \text { Fully } \\ \text { Disagree } & & & & & & \text { Agree }\end{array}$

2 I felt like I was just perceiving pictures.

$\begin{array}{ccccccc}0 & 1 & 2 & 3 & 4 & 5 & 6 \\ \text { Fully } & & & & & & \text { Fully } \\ \text { Disagree } & & & & & & \text { Agree }\end{array}$

$3 \quad$ I did not feel present in the virtual space.

Feel Present Present

$4 \quad$ I had a sense of acting in the virtual space, rather than operating something from outside.

$\begin{array}{ccccccc}0 & 1 & 2 & 3 & 4 & 5 & 6 \\ \text { Fully } & & & & & & \text { Fully } \\ \text { Disagree } & & & & & & \text { Agree }\end{array}$

$5 \quad$ I felt present in the virtual space.

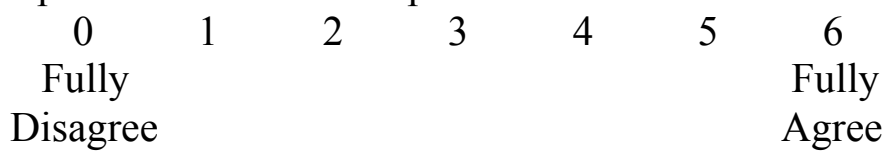

6 How aware were you of the real world surrounding while navigating in the virtual world? (i.e. sounds, room temperature, other people, etc.)?

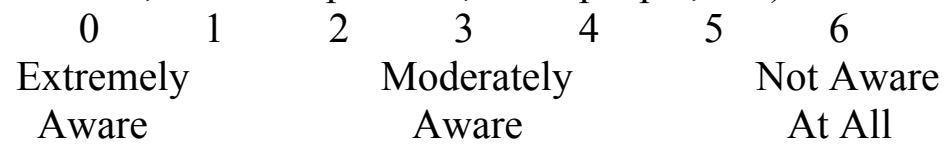


7 I was not aware of my real environment.

$\begin{array}{ccccccc}0 & 1 & 2 & 3 & 4 & 5 & 6 \\ \text { Fully } & & & & & & \text { Fully } \\ \text { Disagree } & & & & & & \text { Agree }\end{array}$

$8 \quad$ I still paid attention to the real environment.

$\begin{array}{ccccccc}0 & 1 & 2 & 3 & 4 & 5 & 6 \\ \text { Fully } & & & & & & \text { Fully } \\ \text { Disagree } & & & & & & \text { Agree }\end{array}$

$9 \quad$ I was completely captivated by the virtual world.

$\begin{array}{ccccccc}0 & 1 & 2 & 3 & 4 & 5 & 6 \\ \text { Fully } & & & & & & \text { Fully } \\ \text { Disagree } & & & & & & \text { Agree }\end{array}$

10 How real did the virtual world seem to you?

$\begin{array}{ccccccc}0 & 1 & 2 & 3 & 4 & 5 & 6 \\ \begin{array}{c}\text { Completely } \\ \text { Real }\end{array} & & & & & \begin{array}{c}\text { Not Real } \\ \text { At All }\end{array}\end{array}$

11 How much did your experience in the virtual environment seem consistent with your real world experience?

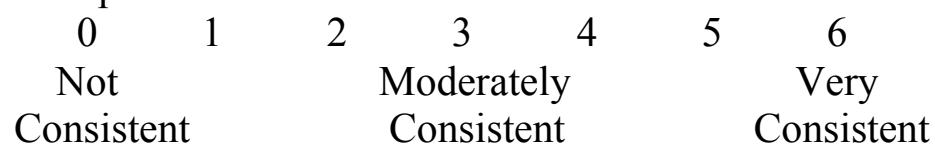

12 How real did the virtual world seem to you?

$\begin{array}{ccccccc}0 & 1 & 2 & 3 & 4 & 5 & 6 \\ \text { About as } & & & & & \text { Indistinguishable } \\ \text { Real As An } & & & & \text { from the real world }\end{array}$

13 The virtual world seemed more realistic than the real world.

$\begin{array}{ccccccc}0 & 1 & 2 & 3 & 4 & 5 & 6 \\ \text { Fully } & & & & & & \text { Fully } \\ \text { Disagree } & & & & & & \text { Agree }\end{array}$




\section{Appendix E}

Abbreviated Acceptability Rating Profile

Directions: The items in this questionnaire refer to the 2 weeks of videos you watched as a treatment for dental fear. Please rate the level you agree to these items by using the following scale.

$\begin{aligned} & \text { Strongly } \\ & \text { Disagree }\end{aligned}$
$\begin{aligned} & \text { This is an acceptable } \\ & \text { treatment for my dental } \\ & \text { fear }\end{aligned}$
$\begin{aligned} & \text { Disagree } \\ & \text { The treatment should be } \\ & \text { effective in changing } \\ & \text { my fear of the dentist }\end{aligned}$




\section{Appendix F}

Steps of the Dental Behavioral Avoidance Task

1) Participant sits in a dental chair waiting for the dentist

2) Dentist walks in and places bib and eyewear on the participant

3) Dentist examines the participants faux dental chart

4) Participant is shown a dental syringe

5) Participant hears a dental drill

6) Dentist puts on gloves, mask, and eyewear

7) Dentist lays the chair back and moves the overhead light over the participant's mouth

8) Dentist asks participant to open mouth and the dentist writes in the faux patient chart

9) Dentist touches the lingual surface of the two most posterior maxillary and mandibular teeth with a tongue depressor 